\title{
Significant clinicopathologic prognostic factors for bladder recurrence, progression, and cancer- specific survival after surgery among patients with upper urinary tract urothelial carcinoma
}

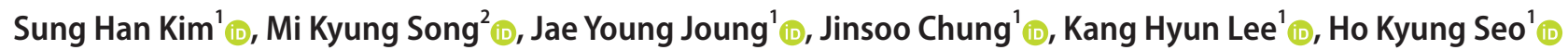 \\ 'Department of Urology, Center for Urologic Cancer, National Cancer Center, Goyang, ${ }^{2}$ Biometrics Research Branch, Division of Cancer Epidemiology and Prevention, \\ Research Institute and Hospital of National Cancer Center, Goyang, Korea
}

Purpose: This study aimed to identify prognostic factors for outcomes after radical nephroureterectomy among patients with upper urinary tract urothelial carcinoma (UTUC).

Materials and Methods: We retrospectively reviewed 184 nonmetastatic cases of UTUC after radical nephroureterectomy, bladder cuffing, and/or partial cystectomy (2004-2016). Bladder recurrence-free survival (BRFS), disease progression-free survival (DPFS), and cancer-specific survival (CSS) were estimated. The prognostic values of clinicopathologic parameters were evaluated by using Cox logistic regression analysis.

Results: The median BRFS, DPFS, and CSS values were 19.0 months, 38.5 months, and 67.0 months, respectively. We identified cases of bladder recurrence (64 cases, 34.8\%), disease progression (54 cases, 29.3\%), and cancer-specific death ( 23 cases, 12.5\%). BRFS was independently associated with lymphovascular invasion (hazard ratio [HR], 0.421); DPFS was associated with intravesical instillation (HR, 0.290), active smoking (HR, 0.367), synchronous bladder lesions (HR, 2.355), and pT2 (HR, 5.199) and pT3 and pT4 $(H R, 13.281)$ stages; and CSS was associated with alkaline phosphatase levels (HR, 0.966). Among 123 cases without previous bladder cancer, DPFS was associated with intravesical instillation (HR, 0.264), multifocal ureteral tumors (HR, 4.823), and pT3 and pT4 stages (HR, 10.899), whereas CSS was associated with pTis (HR, 32.071).

Conclusions: Patients with the factors we identified should receive adjuvant intravesical/systemic chemotherapy and intensive surveillance.

Keywords: Nephroureterectomy; Prognosis; Risk factors; Survival; Ureteral neoplasms

This is an Open Access article distributed under the terms of the Creative Commons Attribution Non-Commercial License (http://creativecommons.org/licenses/by-nc/4.0) which permits unrestricted non-commercial use, distribution, and reproduction in any medium, provided the original work is properly cited.

\section{INTRODUCTION}

Upper urinary tract urothelial carcinoma (UTUC), also known as ureteropelvic cancer, accounts for approximately $5 \%$ to $10 \%$ of urothelial tumors [1-3]. This cancer affects males approximately twofold more frequently than females,

Received: 9 April, 2019 • Accepted: 30 June, 2019

Corresponding Author: Ho Kyung Seo (iD https://orcid.org/0000-0003-2601-1093

Department of Urology, Center for Urologic Cancer, National Cancer Center, 323 Ilsan-ro, Ilsandong-gu, Goyang 10408, Korea

TEL: +82-31-920-1676, FAX: +82-31-920-1790, E-mail: seohk@ncc.re.kr 
and pyelocaliceal tumors are approximately twofold more common than ureteral tumors [4,5]. The gold standard curative treatments are radical nephroureterectomy (RNU) with ipsilateral bladder cuff removal for high-risk cases of UTUC and kidney-sparing surgery with single segmental ureterectomy or endoscopic ablation for low-risk cases. These treatments provide adequate local tumor control and long-term survival [6], although the estimated 5-year survival rates are $<30 \%$ and $<10 \%$ in cases with regional nodal metastases and distant metastases, respectively [3].

Adjuvant chemotherapy for disease recurrence and metastasis is selected on the basis of an optimized follow-up that is scheduled to identify significant clinicopathologic prognostic factors. These factors include tumor stage and positive lymph node status, although they are also affected by the heterogeneity and aggressiveness of the UTUC [4,7-9]. Controversy also exists regarding whether preoperative hydronephrosis, synchronous bladder tumor lesions, and other parameters are significantly related to patient survival or progression of UTUC [2,10-13]. Moreover, the traditional prognostic factors for UTUC after RNU, such as pathologic tumor stage and grade, are inadequate for detailed risk stratification and are difficult to evaluate before treatment [14]. Therefore, the present study aimed to evaluate clinicopathologic, preoperative imaging, laboratory, and intraoperative findings in order to identify factors that could predict bladder recurrence, disease progression, and cancer-specific death after surgery among patients with UTUC.

\section{MATERIALS AND METHODS}

\section{Ethical considerations}

This retrospective study protocol was approved by the Institutional Review Board of the National Cancer Center (approval number: NCC-2016-0241) and complied with the principles of the Declaration of Helsinki. The requirement for written informed consent was waived because of the retrospective design. All patient data and records were anonymized before the analysis.

\section{Patient population}

We retrospectively reviewed data from 184 consecutive patients with nonmetastatic UTUC who underwent RNU with or without bladder cuffing or with partial cystectomy between March 2004 and March 2016. Among the 184 patients, 61 patients had a history of bladder cancer. We excluded patients with nonurothelial cancer, contralateral UTUC, incomplete follow-up data, palliative surgery, and neoadjuvant chemotherapy or radiotherapy. Patients with previous or synchronous non-muscle-invasive bladder cancer were treated using transurethral resection of bladder tumor with or without intravesical instillation therapy. The treatment was selected on the basis of pathologic $\mathrm{T}$ stage and nuclear grade according to the 2009 TNM classification for UTUC and the World Health Organization (WHO)/International Society of Urologic Pathologists (ISUP) consensus classification from 2004.

RNU was performed by use of the open or laparoscopic technique by four different urologists according to the standard surgical methodology (extra-fascial dissection of the kidney with the entire length of the ureter and with or without the adjacent segment of the bladder cuff). Bladder cuffing was omitted for patients older than 75 years at the surgeon's discretion ( $\mathrm{n}=5$ ), for 70 to 75 -year-old patients with newly diagnosed UTUC and no history of urothelial carcinoma ( $\mathrm{n}=12)$, and for patients younger than 70 years with a single, papillary, low-grade mass at the midureter as shown during the preoperative ureteroscopy and imaging scan $(n=5)$. Dissection of the hilar and regional lymph nodes adjacent to the ipsilateral great vessel was performed if the lymph node was intraoperatively palpable or enlarged during the preoperative axial imaging. Adjuvant chemotherapy was administered to 75 patients (40.8\%), who generally had non-organconfined disease (stage 3 to 4 ).

The patients' records were used to obtain data regarding age, sex, and smoking status (intensity, duration, and smoking type); tumor laterality, size, multifocality, and location (renal, pelvic, ureteral, or multiple); and the presence of previous or synchronous non-muscle-invasive bladder cancer. We also collected information regarding intravesical instillation therapy, preoperative laboratory parameters (urine cytology, serum creatinine, lymphocyte-to-monocyte ratio, and De Ritis ratio), and pathologic parameters (tumor stage, grade, positive lymph node status, lymphovascular invasion [LVI, resection margin positivity, carcinoma in situ, and tumor necrosis). Furthermore, we collected data regarding the presence of preoperative hydronephrosis, adjuvant therapy and agents, and surgical parameters (open surgery, laparoscopy, and extravesical or intravesical bladder cuffing). The patients had provided self-reported data regarding smoking status, duration, and intensity (pack-years, years of smoking, and years since smoking cessation). The exposure variable was defined as pack-years, which was calculated as (cigarettes smoked per day/20)×(years smoked). Smoking status was classified as never smoker, former smoker (smoked $<100$ cigarettes during their lifetime), or active smoker (regularly smoked at the time of the diagnosis). However, we did not obtain information regarding smoking style, product brand, 
Table 1. Baseline characteristics of 184 patients with upper urinary urothelial carcinoma, including 61 patients with a history of bladder cancer

\begin{tabular}{|c|c|c|}
\hline Variable & Total data set $(n=184)$ & $\begin{array}{c}\text { Upper urinary tract cancer } \\
\text { without bladder cancer }(n=123)\end{array}$ \\
\hline Age (y) & $67.50(24.00-87.00)$ & $67.00(24.00-87.00)$ \\
\hline Sex (male/female) & $135 / 49(73.4 / 26.6)$ & $85 / 38(69.1 / 30.9)$ \\
\hline $\mathrm{BMI}\left(\mathrm{kg} / \mathrm{m}^{2}\right)$ & $24.20(15.80-33.40)$ & $24.20(15.80-33.40)$ \\
\hline Hypertension & $81(44.0)$ & $56(45.5)$ \\
\hline Diabetes & $24(13.0)$ & $11(8.9)$ \\
\hline \multicolumn{3}{|l|}{ Bladder cancer status } \\
\hline None & $123(66.8)$ & - \\
\hline Previous bladder tumor history & $53(28.8)$ & - \\
\hline Concomitant bladder tumor history & $8(4.3)$ & - \\
\hline Intravesical instillation history & $66(35.9)$ & $33(26.8)$ \\
\hline Preoperative instillation & $33(50.0)$ & \\
\hline Postoperative instillation & $33(50.0)$ & $33(26.8)$ \\
\hline Preoperative hydronephrosis & $100(54.3)$ & $66(53.7)$ \\
\hline Preoperative ureteroscopy & $45(24.5)$ & $27(22.0)$ \\
\hline \multicolumn{3}{|l|}{ ASA } \\
\hline 1 & $39(21.2)$ & $25(20.3)$ \\
\hline 2 & $119(64.7)$ & $80(65.0)$ \\
\hline 3 & $15(8.2)$ & $9(7.3)$ \\
\hline \multicolumn{3}{|l|}{ Smoking status } \\
\hline Never smokers & $71(38.6)$ & $59(48.0)$ \\
\hline Former smokers & $62(33.7)$ & $34(27.6)$ \\
\hline Active smokers & $51(27.7)$ & $30(24.4)$ \\
\hline Duration smoked $(\mathrm{y})$ & $28.00(2.00-66.00)$ & $20.00(0.00-66.00)$ \\
\hline \multicolumn{3}{|l|}{ Duration smoked } \\
\hline Never smoked & $71(38.6)$ & $59(48.0)$ \\
\hline$<40$ years & $58(31.5)$ & $31(25.2)$ \\
\hline$\geq 40$ years & $55(29.9)$ & $33(26.8)$ \\
\hline \multicolumn{3}{|l|}{ Intensity smoked } \\
\hline Never smoked & $71(38.6)$ & $59(48.0)$ \\
\hline$<1$ pack-year & $36(19.6)$ & $19(15.4)$ \\
\hline$\geq 1$ pack-year & $76(41.3)$ & $44(35.8)$ \\
\hline \multicolumn{3}{|l|}{ Preoperative laboratory } \\
\hline Creatinine $(\mathrm{mg} / \mathrm{dL})$ & $1.20(0.56-31.00)$ & $1.20(0.56-31.00)$ \\
\hline Alanine transaminase (IU/L) & $20.00(9.00-196.00)$ & $19.50(9.00-196.00)$ \\
\hline Alanine aminotransferase (IU/L) & $15.00(1.30-291.00)$ & $15.00(1.30-291.00)$ \\
\hline Alkaline phosphatase (IU/L) & $77.00(36.00-206.00)$ & $77.00(36.00-206.00)$ \\
\hline \multicolumn{3}{|l|}{ Operative findings } \\
\hline \multicolumn{3}{|l|}{ Operative method } \\
\hline Open & $104(56.5)$ & $62(50.4)$ \\
\hline Laparoscopy & $80(43.5)$ & $61(49.6)$ \\
\hline \multicolumn{3}{|l|}{ Cuffing method } \\
\hline None & $22(12.1)$ & $12(9.9)$ \\
\hline Intravesical & $3(1.6)$ & $2(1.7)$ \\
\hline Extravesical & $147(80.8)$ & $107(88.4)$ \\
\hline Partial cystectomy & $10(5.5)$ & $0(0.0)$ \\
\hline Hospital stay & $13.00(3.00-104.00)$ & $12.00(3.00-104.00)$ \\
\hline \multicolumn{3}{|l|}{ Pathologic findings } \\
\hline \multicolumn{3}{|l|}{ Tumor location } \\
\hline Single renal pelvic site & $75(41.0)$ & $61(49.6)$ \\
\hline Single ureter site & $69(37.7)$ & $44(35.8)$ \\
\hline Multiple sites & $39(21.3)$ & $18(14.6)$ \\
\hline Multifocality & $26(14.2)$ & $11(8.9)$ \\
\hline
\end{tabular}


Table 1. Continued

\begin{tabular}{|c|c|c|}
\hline Variable & Total data set $(n=184)$ & $\begin{array}{c}\text { Upper urinary tract cancer } \\
\text { without bladder cancer }(n=123)\end{array}$ \\
\hline \multicolumn{3}{|l|}{ Tumor grade (1973 WHO classification) } \\
\hline 1 & $5(3.0)$ & $5(4.5)$ \\
\hline 2 & $58(35.4)$ & $38(34.5)$ \\
\hline 3 & $101(61.6)$ & $67(60.9)$ \\
\hline \multicolumn{3}{|c|}{ Tumor grade (2004 WHO/ISUP classification) } \\
\hline Low & $33(20.1)$ & $21(19.1)$ \\
\hline High & $131(79.9)$ & $89(80.9)$ \\
\hline Pathologic T stage (missing) & 11 & 7 \\
\hline $\mathrm{Ta}+\mathrm{T} 1$ & $36(20.8)$ & $25(21.6)$ \\
\hline $\mathrm{T} 2$ & $45(26.0)$ & $30(25.9)$ \\
\hline $\mathrm{T} 3+\mathrm{T} 4$ & $89(51.4)$ & $50(43.1)$ \\
\hline Carcinoma in situ only & $3(1.7)$ & $2(1.7)$ \\
\hline Carcinoma in situ & $29(15.9)$ & $18(14.6)$ \\
\hline Lymphovascular invasion & $50(28.3)$ & $35(30.0)$ \\
\hline Tumor necrosis & $15(8.2)$ & $12(9.8)$ \\
\hline Pathologic $\mathrm{N}$ stage (missing) & 4 & 3 \\
\hline $\mathrm{Nx}$ & $106(58.9)$ & $68(56.7)$ \\
\hline No & $59(32.8)$ & $39(32.5)$ \\
\hline $\mathrm{N} 1+\mathrm{N} 2$ & $15(8.3)$ & $13(10.8)$ \\
\hline Tumor size $(>2.5 \mathrm{~cm})$ & $132(73.3)$ & $92(75.4)$ \\
\hline Resection margin positive (positive) & $33(18.3)$ & $23(18.7)$ \\
\hline \multicolumn{3}{|l|}{ Survival outcomes } \\
\hline Bladder recurrence & $64(34.8)$ & $37(30.1)$ \\
\hline Time to bladder recurrence (mo) & $19.00(0.00-160.00)$ & $20.00(0.00-154.00)$ \\
\hline Progression & $54(29.3)$ & $36(29.3)$ \\
\hline Time to progression (mo) & $38.50(0.00-160.00)$ & $39.00(0.00-159.00)$ \\
\hline Cancer-specific death & $23(12.5)$ & $13(10.6)$ \\
\hline Time to cancer-specific survival (mo) & $67.00(0.00-160.00)$ & $62.00(0.00-159.00)$ \\
\hline Adjuvant chemotherapy & $75(40.8)$ & $49(39.8)$ \\
\hline Palliative chemotherapy & $30(16.3)$ & $20(16.3)$ \\
\hline
\end{tabular}

Values are presented as median (range), number (\%), or number only. BMI, body mass index; ASA, American Society of Anesthesiologists; WHO, World Health Organization; ISUP, International Society of Urologic Pathologists; -, not applicable.

or degree of inhalation.

All specimens from the patients were histologically confirmed to be urothelial carcinoma by a genitourinary oncopathologist with 15 years of experience. Multifocality was defined as the synchronous presence of $\geq 2$ pathologically confirmed macroscopic tumors in the upper urinary tract. Preoperative hydronephrosis was determined by using computed tomography, magnetic resonance imaging, or ultrasonography.

\section{Follow-up schedule}

Patients were generally evaluated every 3 months during the first year after the RNU, every 6 months during years 2 to 5 , and annually thereafter. Cystoscopy, blood tests, and urine tests (including urine cytology) were included in the routine surveillance protocol. Abdominal and chest computed tomography or magnetic resonance imaging was suggested annually or more often, depending on the clinical stage. Other protocols, including urinary cytology, ultrasonography, magnetic resonance imaging, and elective bone scans, were performed when clinically indicated. Cases of death were determined by reviewing records from the National Cancer Registry.

\section{Statistical analysis}

All continuous data were presented as median and range, and all categorical data were reported as number and percentage. Univariate and multivariable Cox proportional- 
hazard models were used to explore risk factors for bladder recurrence-free survival (BRFS), disease progression-free survival (DPFS), and cancer-specific survival (CSS) after RNU among the 184 patients with UTUC. Additional subgroup analyses of BRFS, DPFS, and CSS were performed for the 123 patients without a history of bladder cancer to exclude the effects of having a history of bladder cancer and to identify differences in outcomes according to the presence of previous bladder cancer. The variables that were included in the multivariable Cox proportional-hazard models were selected from the univariate analyses based on $\mathrm{p}$-values of $<0.05$. Statistical analyses were performed using SAS software (version 9.4; SAS Inc., Cary, NC, USA). Differences with a two-tailed $\mathrm{p}$-value of $<0.05$ were considered statistically significant.

\section{RESULTS}

The patients' baseline clinicopathologic and intraoperative characteristics are shown in Table 1 . The patients' median age was 67.5 years, and the ratio of open/laparoscopic nephrectomies was 104/80 (56.5\%/43.5\%). Approximately 80\% of the patients had high-grade tumors, $51.4 \%$ had a pathologic T stage of $\geq \mathrm{T} 3$, and $8.3 \%$ had a pathologic N stage of N1-2. A total of 71 patients were never smokers (38.6\%), 62 patients were former smokers (33.7\%), and 51 patients were active smokers (27.7\%). Intravesical instillation was performed for 66 patients (35.9\%), including 33 patients (50.0\%) with newly diagnosed UUTC and no history of bladder cancer and another 33 patients $(50.0 \%)$ who had received instillation before nephroureterectomy because of a previous bladder cancer. During a median follow-up of 36.5 months, we detected bladder recurrence after the RNU (64 patients, 34.8\%), disease progression (54 patients, 29.3\%), death (49 patients, $26.6 \%$ ), and cancer-specific death (23 patients, 12.5\%). The median BRFS, DPFS, and CSS values were 19.0 months, 38.5 months, and 67.0 months, respectively (Table 1).

The multivariable Cox proportional-hazard analysis revealed that BRFS was independently associated with LVI (hazard ratio [HR], 0.421; 95\% confidence interval [CI], 0.1940.917) ( $p=0.029$, Table 2, Supplementary Table 1). DPFS was independently associated with intravesical instillation (HR, 0.290; 95\% CI, 0.087-0.964), active smoking (HR, 0.367; 95\% CI, 0.143-0.946), concomitant bladder lesions (HR, 2.355; 95\% CI,

Table 2. Multivariate analysis of risk factors for recurrence in the bladder among the 184 patients and the 123 patients without a history of bladder cancer

\begin{tabular}{|c|c|c|c|c|}
\hline \multirow{3}{*}{ Variable } & \multicolumn{2}{|c|}{ Total data set $(n=184)$} & \multicolumn{2}{|c|}{ No previous bladder cancer $(n=123)$} \\
\hline & \multicolumn{2}{|c|}{ Multivariate } & \multicolumn{2}{|c|}{ Multivariate } \\
\hline & $\mathrm{HR}(95 \% \mathrm{Cl})$ & p-value & $\mathrm{HR}(95 \% \mathrm{Cl})$ & p-value \\
\hline Hypertension & $1.728(0.980-3.046)$ & 0.0587 & $1.692(0.814-3.517)$ & 0.1591 \\
\hline Diabetes & $1.268(0.577-2.783)$ & 0.5547 & & \\
\hline Bladder cancer status (no) & 1 (Ref.) & & & \\
\hline Previous bladder tumor & $1.439(0.780-2.654)$ & 0.2444 & & \\
\hline Concomitant bladder tumor & $0.219(0.025-1.920)$ & 0.1702 & & \\
\hline Preoperative hydronephrosis & & & $1.808(0.843-3.875)$ & 0.1280 \\
\hline \multicolumn{5}{|l|}{ Smoking status } \\
\hline Never smokers & 1 (Ref.) & & & \\
\hline Former smokers & $1.534(0.797-2.953)$ & 0.2004 & & \\
\hline Active smokers & $0.745(0.351-1.581)$ & 0.4438 & & \\
\hline Alanine transaminase & $1.004(0.997-1.010)$ & 0.2909 & $1.003(0.997-1.010)$ & 0.3481 \\
\hline \multicolumn{5}{|l|}{ Tumor location } \\
\hline Single renal pelvic site & 1 (Ref.) & & & \\
\hline Single ureter site & $0.869(0.466-1.623)$ & 0.6600 & & \\
\hline Multiple sites & $1.596(0.750-3.396)$ & 0.2255 & & \\
\hline Lymphovascular invasion & $0.421(0.194-0.917)$ & 0.0294 & & \\
\hline \multicolumn{5}{|l|}{ Pathologic T stage } \\
\hline $\mathrm{Ta}+\mathrm{T} 1$ & 1 (Ref.) & & 1 (Ref.) & \\
\hline $\mathrm{T} 2$ & $0.860(0.430-1.717)$ & 0.6685 & $0.858(0.349-2.112)$ & 0.7393 \\
\hline $\mathrm{T} 3+\mathrm{T} 4$ & $0.616(0.308-1.233)$ & 0.1716 & $0.605(0.254-1.441)$ & 0.2564 \\
\hline Carcinoma in situ only & $1.670(0.301-9.257)$ & 0.5574 & $4.344(0.886-21.297)$ & 0.0701 \\
\hline
\end{tabular}

$\mathrm{HR}$, hazard ratio; $\mathrm{Cl}$, confidence interval; Ref., reference. 
1.033-5.370), pT2 stage (HR, 5.199; 95\% CI, 1.003-26.942), and pT3 and pT4 stages (HR, 13.281; 95\% CI, 2.708-65.144; p<0.05, Table 3, Supplementary Table 2). CSS was independently associated with alkaline phosphatase (ALP) levels (HR, 0.966; 95\% CI, 0.939-0.994; p=0.017) (Table 4, Supplementary Table 3). Additional subanalyses of the 123 patients with UTUC and no history of bladder cancer revealed that no factors were independently associated with BRFS ( $>>0.05$, Table 2). In those subanalyses, DPFS was independently associated with intravesical instillation (HR, 0.264; 95\% CI, 0.076-0.917), multifocal ureteral tumors (HR, 4.823; 95\% CI, 1.457-15.969), and pT3 and pT4 stages (HR, 10.899; 95\% CI, 1.342-88.535; p<0.05) (Table 3), whereas CSS was independently associated with p'Tis (HR, 32.071; 95\% CI, 1.869-550.373; p<0.05) (Table 4).

\section{DISCUSSION}

Similar to urothelial bladder carcinoma, UTUC is highly recurrent and costly to treat, despite its low prevalence. Thus, it is an important public health priority to understand the risk factors for recurrence, progression, and survival. The present study evaluated various laboratory, pathologic,

Table 3. Multivariate analysis of risk factors for disease progression among the 184 patients and the 123 patients without a history of bladder cancer

\begin{tabular}{|c|c|c|c|c|}
\hline \multirow{3}{*}{ Variable } & \multicolumn{2}{|c|}{ Total data set $(n=184)$} & \multicolumn{2}{|c|}{ No previous bladder cancer $(n=123)$} \\
\hline & \multicolumn{2}{|c|}{ Multivariate } & \multicolumn{2}{|c|}{ Multivariate } \\
\hline & $\mathrm{HR}(95 \% \mathrm{Cl})$ & p-value & $\mathrm{HR}(95 \% \mathrm{Cl})$ & p-value \\
\hline Intravesical instillation history & $0.290(0.087-0.964)$ & 0.0434 & $0.264(0.076-0.917)$ & 0.0361 \\
\hline \multicolumn{5}{|l|}{ Smoking status } \\
\hline Never smokers & 1 (Ref.) & & & \\
\hline Former smokers & $1.264(0.576-2.775)$ & 0.5593 & & \\
\hline Active smokers & $0.367(0.143-0.946)$ & 0.0381 & & \\
\hline Hemoglobin & $0.916(0.717-1.170)$ & 0.4824 & $0.913(0.667-1.249)$ & 0.5679 \\
\hline Lymphocyte & $0.990(0.960-1.021)$ & 0.5103 & $0.996(0.957-1.036)$ & 0.8325 \\
\hline Platelet & $0.998(0.992-1.003)$ & 0.4123 & & \\
\hline Calcium & & & $1.135(0.296-4.359)$ & 0.8534 \\
\hline Albumin & $0.784(0.354-1.736)$ & 0.5489 & $0.517(0.090-2.978)$ & 0.4602 \\
\hline Alanine transaminase & & & $1.002(0.973-1.032)$ & 0.8965 \\
\hline Concomitant bladder lesion & $2.355(1.033-5.370)$ & 0.0417 & & \\
\hline \multicolumn{5}{|l|}{ Tumor location } \\
\hline Single renal pelvic site & 1 (Ref.) & & & \\
\hline Single ureter site & $1.295(0.608-2.757)$ & 0.5024 & & \\
\hline Multiple sites & $1.462(0.559-3.825)$ & 0.4392 & & \\
\hline Multifocality & & & $4.823(1.457-15.969)$ & 0.0100 \\
\hline \multicolumn{5}{|c|}{ Tumor grade (2004 WHO/ISUP classification) } \\
\hline Low & 1 (Ref.) & & & \\
\hline High & $0.625(0.224-1.740)$ & 0.3680 & & \\
\hline \multicolumn{5}{|l|}{ Pathologic T stage } \\
\hline $\mathrm{Ta}+\mathrm{T} 1$ & 1 (Ref.) & & 1 (Ref.) & \\
\hline $\mathrm{T} 2$ & $5.199(1.003-26.942)$ & 0.0496 & $5.378(0.593-48.803)$ & 0.1349 \\
\hline $\mathrm{T} 3+\mathrm{T} 4$ & $13.281(2.708-65.144)$ & 0.0014 & $10.899(1.342-88.535)$ & 0.0254 \\
\hline Carcinoma in situ only & $0.000(0.000-\mathrm{NA})$ & 0.9900 & $0.000(0.000-N A)$ & 0.9922 \\
\hline Carcinoma in situ & $1.025(0.458-2.294)$ & 0.9529 & $1.209(0.490-2.984)$ & 0.6806 \\
\hline Lymphovascular invasion & $0.873(0.429-1.776)$ & 0.7081 & $1.237(0.570-2.684)$ & 0.5912 \\
\hline Tumor necrosis & $1.449(0.441-4.758)$ & 0.5411 & & \\
\hline Pathologic $\mathrm{N}$ stage $(\mathrm{Nx})$ & 1 (Ref.) & & 1 (Ref.) & \\
\hline No & $0.613(0.291-1.292)$ & 0.1984 & $0.519(0.210-1.284)$ & 0.1559 \\
\hline $\mathrm{N} 1+\mathrm{N} 2$ & $1.452(0.424-4.979)$ & 0.5527 & $1.554(0.536-4.504)$ & 0.4170 \\
\hline Resection margin positive & & & $1.610(0.546-4.741)$ & 0.3878 \\
\hline Bladder recurrence & $1.264(0.409-3.901)$ & 0.6839 & & \\
\hline
\end{tabular}

HR, hazard ratio; Cl, confidence interval; Ref., reference; WHO, World Health Organization; ISUP, International Society of Urologic Pathologists; NA, not applicable. 
Table 4. Multivariate analysis of risk factors for cancer-specific survival among the 184 patients and the 123 patients without a history of bladder cancer

\begin{tabular}{|c|c|c|c|c|}
\hline \multirow{3}{*}{ Variable } & \multicolumn{2}{|c|}{ Total data set $(n=184)$} & \multicolumn{2}{|c|}{ No previous bladder cancer $(n=123)$} \\
\hline & \multicolumn{2}{|c|}{ Multivariate } & \multicolumn{2}{|c|}{ Multivariate } \\
\hline & HR $(95 \% \mathrm{Cl})$ & p-value & HR $(95 \% \mathrm{Cl})$ & p-value \\
\hline Diabetes & & & $5.388(0.975-29.765)$ & 0.0535 \\
\hline Alkaline phosphatase & $0.966(0.939-0.994)$ & 0.0171 & & \\
\hline \multicolumn{5}{|l|}{ Tumor location } \\
\hline Single renal pelvic site & 1 (Ref.) & & & \\
\hline Single ureter site & $1.707(0.528-5.515)$ & 0.3713 & & \\
\hline Multiple sites & $2.060(0.511-8.303)$ & 0.3095 & & \\
\hline Multifocality & $3.103(0.893-10.786)$ & 0.0749 & & \\
\hline \multicolumn{5}{|l|}{ Pathologic T stage } \\
\hline $\mathrm{Ta}+\mathrm{T} 1$ & & & 1 (Ref.) & \\
\hline $\mathrm{T} 2$ & & & $1.555(0.095-25.598)$ & 0.7572 \\
\hline $\mathrm{T} 3+\mathrm{T} 4$ & & & $5.695(0.722-44.937)$ & 0.0988 \\
\hline Carcinoma in situ only & & & $32.071(1.869-550.373)$ & 0.0168 \\
\hline
\end{tabular}

$\mathrm{HR}$, hazard ratio; $\mathrm{Cl}$, confidence interval; Ref., reference.

operative, and adjuvant treatment factors that might predict BRFS, DPFS, and CSS after RNU for UTUC. Some of the known prognostic parameters were significant in the univariate analyses, although the multivariate analyses revealed that they did not independently predict prognosis. Furthermore, the results were significantly different between the 123 patients without a history of bladder cancer and the group of 184 patients. In the group of 184 patients, BRFS was independently predicted by LVI (HR, 0.421); DPFS was independently predicted by intravesical instillation (HR, 0.290), active smoking (HR, 0.367), concomitant bladder lesions (HR, 2.355), and pT2 (HR, 5.199) and pT3 and pT4 (HR, 13.281) stages; and CSS was independently predicted by ALP levels (HR, 0.966). However, in the 123 patients without a history of bladder cancer, no factors independently predicted BRFS, whereas DPFS was independently predicted by intravesical instillation (HR, 0.264), multifocal ureteral tumors (HR, 4.823), and pT3 and pT4 stages (HR, 10.899), and CSS was independently predicted by pTis (HR, 32.071). Despite these differences, the common factors in both groups were pathologic T2 to T4 stages, multifocal ureteral tumors, concomitant bladder lesions, and intravesical instillation. Similar results have been reported in previous studies of the prognostic factors for UTUC [2,15-19].

The pathologic T stage is useful for risk stratification, as higher pathologic stages are associated with poor prognoses after RNU [3,4,6], and the present study also revealed that pathologic T2 to T4 stages predicted DPFS ( $p<0.05$, Table 3 ). A previous study revealed that approximately $30 \%$ of patients with UTUC had a history of bladder cancer, similar to the findings of the present study (33.2\%), and synchro- nous tumors were observed in approximately $8 \%$ to $13 \%$ of those cases (vs. $16.85 \%$ in the present study, data not shown) [20]. Liang et al. [2] evaluated 172 patients with UTUC who underwent RNU and found that BRFS was significantly associated with multifocality and previous or synchronous non-muscle-invasive bladder cancer $(p<0.05)$. Pignot et al. [21] reported that patients with previous or synchronous bladder cancer are more likely to develop bladder recurrence, which leads to a higher rate of intravesical instillation to prevent bladder recurrence. Mathieu et al. [22] also performed a nonsystematic literature review and found that post-RNU intravesical instillation can decrease the rate of bladder cancer recurrence. Furthermore, the present study revealed that intravesical instillation predicted DPFS, which is presumably related to patients with intravesical instillation having higher-risk bladder cancer with more aggressive pathology and poorer outcomes that are related to the greater tumor burden. These patients would receive closer surveillance and follow-up using regular, systematic clinical and cystoscopic evaluations, which would result in an earlier diagnosis and treatment of the UTUC and subsequently lead to better outcomes after early surgical intervention. Thus, routine follow-up of patients who undergo intravesical installation is recommended to prevent the progression of UTUC.

In addition to the previously mentioned prognostic factors, smoking is a known oncogenic factor for urinary urothelial carcinoma, including UTUC, and people with any history of smoking have a 2 - to 4 -fold increased risk of these cancers [23-25]. Rink et al. [26] also reported that cigarette smoking was significantly associated with advanced disease stages, recurrence, and survival among patients who under- 
went RNU for UTUC. However, the mechanism or mechanisms by which aromatic amine-like chemicals promote carcinogenesis, cause recurrence and progression, and reduce survival remain unclear [24]. Interestingly, the present study revealed that active smoking was significantly associated with prolonged DPFS (HR, 0.367; $\mathrm{p}=0.038$; Table 3), which conflicts with the current consensus that active smoking is associated with poorer survival outcomes. This is likely because the active smoking group had lower rates of diabetes, hypertension, and high-grade tumors (18.8\%), compared with the former smoker group (33.7\%) and the never smoker group (38.6\%). Thus, the inverse association with DPFS might be the result of the active smokers being relatively healthy compared with the other groups. However, active smoking was a significant factor only among the group of 184 patients and was not a significant factor among the 123 patients with UTUC and no history of bladder cancer. Thus, the prognostic significance of active smoking is likely related to the risk factors for bladder cancer, rather than the risk factors for UTUC (Table 3). Furthermore, the present study did not examine smoking intensity, volume, duration, or duration of smoking cessation, which have been reported to be associated with poor oncologic outcomes among patients with UTUC $(p>0.05)[24,26]$.

The present study revealed that LVI was inversely associated with BRFS (HR, 0.421), which conflicts with the findings of previous studies [27,28]. Hurel et al. [27] reported that LVI predicted a poor prognosis in patients with urinary urothelial carcinoma or UTUC and that it was an independent predictor of CSS (HR, 173) and metastasis-free or progression-free survival $(\mathrm{HR}, 2.14)$ but did not significantly predict BRFS (HR, 1.27; $\mathrm{p}=0.19)$. Ouzzane et al. [28] also reported that LVI was significantly associated with metastasis (HR, 1.73) but was not associated with CSS (HR, 0.95) or disease-recurrence-free survival $(\mathrm{HR}, 1.26)$ in their multicenter retrospective analysis. Thus, stratified analyses are needed to identify the subgroups of patients with LVI who can expect a favorable outcome after bladder recurrence.

The present study also revealed that CSS was significantly predicted by ALP levels (HR, 0.966) among the group of 184 patients and by pTis stage (HR, 32.071) among the 123 patients without a history of bladder cancer $(p<0.05$, Table 4). In contrast with the results of a previous study [1], the present study revealed that high ALP levels were associated with favorable CSS outcomes, which might be related to the relatively small subgroup of patients with elevated ALP levels (only 3.8\% of patients had ALP levels of $>129$ IU/L). In this context, ALP is a well-known enzyme, and high levels are associated with poor outcomes and cancer cell prolifera- tion in various non-liver cancers. Furthermore, UUTC with high ALP levels tends to recur and progress, which suggests that active treatments after surgery might provide favorable survival outcomes [29]. Among the 123 patients without a history of bladder cancer, pTis significantly predicted CSS (HR, 32.071; $p=0.0168$; Table 4), and similar results were reported in a previous study [17]. However, another study revealed that Tis was more strongly associated with BRFS [7] while the present study revealed that Tis was significantly associated with CSS.

The present study had several limitations. First, the nonrandomized retrospective design and relatively small sample size are associated with inherent risks of bias. Second, we did not have adequate data to evaluate any parameters that were related to preoperative radiographic findings, extent and yield of lymph nodal dissection, adjuvant chemotherapeutic agents, tissue markers, or follow-up factors.

Third, the present study did not identify significant relationships between BRFS and known prognostic factors, such as concomitant bladder cancer and a history of bladder cancer ( $p>0.05$, data not shown), which conflicts with previously reported data [17,19]. This discrepancy may be related to differences in the cohorts or the small sample size. Therefore, further large-scale cohort studies are needed to validate the relationships between BRFS and these factors in Korean patients who undergo nephroureterectomy.

\section{CONCLUSIONS}

The present study identified several significant clinicopathologic prognostic factors for BRFS, DPFS, and CSS among patients who underwent RNU for UTUC. These results suggest that it may be appropriate to consider adjuvant intravesical or systemic chemotherapy and intensive surveillance for patients with these characteristics, especially patients who have a history of smoking. In addition, we observed that bladder recurrence after RNU among patients with UTUC was not strongly associated with DPFS or CSS. Therefore, large cohort studies are needed to examine the factors that may interfere with this relationship.

\section{CONFLICTS OF INTEREST}

The authors have nothing to disclose.

\section{ACKNOWLEDGMENTS}

We thank Ms. Eun Ji Lee for creating the database and performing the sorting processes. 
This work was supported by a grant (NCC1610230) from the National Cancer Center of the Republic of Korea.

\section{SUPPLEMENTARY MATERIALS}

Scan this QR code to see the supplementary materials, or visit https://www.icurology.org/src/sm/icurology-60-432-s001.pdf.

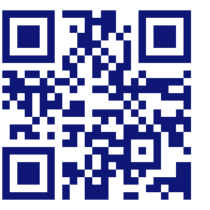

\section{REFERENCES}

1. Lehmann J, Suttmann H, Kovac I, Hack M, Kamradt J, Siemer $S$, et al. Transitional cell carcinoma of the ureter: prognostic factors influencing progression and survival. Eur Urol 2007;51:1281-8.

2. Liang C, Chi R, Huang L, Wang J, Liu H, Xu D, et al. Upper tract urothelial carcinomas accompanied by previous or synchronous nonmuscle-invasive bladder cancer and preoperative hydronephrosis might have worse oncologic outcomes after radical nephroureterectomy. Clin Genitourin Cancer 2016; 14:e469-77.

3. Raman JD, Scherr DS. Management of patients with upper urinary tract transitional cell carcinoma. Nat Clin Pract Urol 2007;4:432-43.

4. Margulis V, Shariat SF, Matin SF, Kamat AM, Zigeuner R, Kikuchi E, et al.; the Upper Tract Urothelial Carcinoma Collaboration. Outcomes of radical nephroureterectomy: a series from the Upper Tract Urothelial Carcinoma Collaboration. Cancer 2009;115:1224-33.

5. Verhoest G, Shariat SF, Chromecki TF, Raman JD, Margulis V, Novara G, et al. Predictive factors of recurrence and survival of upper tract urothelial carcinomas. World J Urol 2011;29:495501.

6. Rouprêt M, Babjuk M, Compérat E, Zigeuner R, Sylvester RJ, Burger M, et al. European Association of Urology guidelines on upper urinary tract urothelial cell carcinoma: 2015 update. Eur Urol 2015;68:868-79.

7. Cha EK, Shariat SF, Kormaksson M, Novara G, Chromecki TF, Scherr DS, et al. Predicting clinical outcomes after radical nephroureterectomy for upper tract urothelial carcinoma. Eur Urol 2012;61:818-25.

8. Morizane S, Yumioka T, Yamaguchi N, Masago T, Honda M, Sejima T, et al. Risk stratification model, including preoperative serum C-reactive protein and estimated glomerular filtration rate levels, in patients with upper urinary tract urothelial carcinoma undergoing radical nephroureterectomy. Int Urol Nephrol 2015;47:1335-41.

9. Yates DR, Hupertan V, Colin P, Ouzzane A, Descazeaud A, Long JA, et al.; French collaborative national database on UUT-UC. Cancer-specific survival after radical nephroureterectomy for upper urinary tract urothelial carcinoma: proposal and multi-institutional validation of a post-operative nomogram. Br J Cancer 2012;106:1083-8.

10. Cho KS, Hong SJ, Cho NH, Choi YD. Grade of hydronephrosis and tumor diameter as preoperative prognostic factors in ureteral transitional cell carcinoma. Urology 2007;70:662-6.

11. Chung PH, Krabbe LM, Darwish OM, Westerman ME, Bagrodia A, Gayed BA, et al. Degree of hydronephrosis predicts adverse pathological features and worse oncologic outcomes in patients with high-grade urothelial carcinoma of the upper urinary tract. Urol Oncol 2014;32:981-8.

12. Hwang I, Jung SI, Nam DH, Hwang EC, Kang TW, Kwon DD, et al. Preoperative hydronephrosis and diabetes mellitus predict poor prognosis in upper urinary tract urothelial carcinoma. Can Urol Assoc J 2013;7:E215-20.

13. Zhang X, Zhu Z, Zhong S, Xu T, Shen Z. Ureteral tumours showing a worse prognosis than renal pelvis tumours may be attributed to ureteral tumours more likely to have hydronephrosis and less likely to have haematuria. World J Urol 2013;31:155-60.

14. Li CC, Chang TH, Wu WJ, Ke HL, Huang SP, Tsai PC, et al. Significant predictive factors for prognosis of primary upper urinary tract cancer after radical nephroureterectomy in Taiwanese patients. Eur Urol 2008;54:1127-34.

15. Kim BW, Ha YS, Lee JN, Kim HT, Kim TH, Lee JK, et al. Effects of previous or synchronous non-muscle invasive bladder cancer on clinical results after radical nephroureterectomy for upper tract urothelial carcinoma: a multi-institutional study. Urol J 2015;12:2233-9.

16. Favaretto RL, Shariat SF, Chade DC, Godoy G, Adamy A, Kaag $\mathrm{M}$, et al. The effect of tumor location on prognosis in patients treated with radical nephroureterectomy at Memorial SloanKettering Cancer Center. Eur Urol 2010;58:574-80.

17. Otto W, Shariat SF, Fritsche HM, Gupta A, Matsumoto K, Kassouf W, et al. Concomitant carcinoma in situ as an independent prognostic parameter for recurrence and survival in upper tract urothelial carcinoma: a multicenter analysis of 772 patients. World J Urol 2011;29:487-94.

18. Xylinas E, Kluth LA, Rieken M, Lee RK, Elghouayel M, Ficarra V, et al.; UTUC Collaboration. Impact of smoking status and cumulative exposure on intravesical recurrence of upper tract urothelial carcinoma after radical nephroureterectomy. BJU Int 2014;114:56-61.

19. Nuhn P, Novara G, Seitz C, Gupta A, Matsumoto K, Kassouf W, 
et al. Prognostic value of prior history of urothelial carcinoma of the bladder in patients with upper urinary tract urothelial carcinoma: results from a retrospective multicenter study. World J Urol 2015;33:1005-13.

20. Hall MC, Womack S, Sagalowsky AI, Carmody T, Erickstad MD, Roehrborn CG. Prognostic factors, recurrence, and survival in transitional cell carcinoma of the upper urinary tract: a 30-year experience in 252 patients. Urology 1998;52:594-601.

21. Pignot G, Colin P, Zerbib M, Audenet F, Soulié M, Hurel S, et al.; French Collaborative National Database on UUT-UC. Influence of previous or synchronous bladder cancer on oncologic outcomes after radical nephroureterectomy for upper urinary tract urothelial carcinoma. Urol Oncol 2014;32:23.e18.

22. Mathieu R, Bensalah K, Lucca I, Mbeutcha A, Rouprêt M, Shariat SF. Upper urinary tract disease: what we know today and unmet needs. Transl Androl Urol 2015;4:261-72.

23. Freedman ND, Silverman DT, Hollenbeck AR, Schatzkin A, Abnet CC. Association between smoking and risk of bladder cancer among men and women. JAMA 2011;306:737-45.

24. Crivelli JJ, Xylinas E, Kluth LA, Rieken M, Rink M, Shariat SF. Effect of smoking on outcomes of urothelial carcinoma: a systematic review of the literature. Eur Urol 2014;65:742-54.

25. Jensen OM, Knudsen JB, McLaughlin JK, Sørensen BL. The
Copenhagen case-control study of renal pelvis and ureter cancer: role of smoking and occupational exposures. Int J Cancer 1988;41:557-61.

26. Rink M, Xylinas E, Margulis V, Cha EK, Ehdaie B, Raman JD, et al.; Upper Tract Urothelial Carcinoma Collaboration. Impact of smoking on oncologic outcomes of upper tract urothelial carcinoma after radical nephroureterectomy. Eur Urol 2013;63:1082-90.

27. Hurel S, Rouprêt M, Ouzzane A, Rozet F, Xylinas E, Zerbib M, et al.; French Collaborative National Database on UTUC. Impact of lymphovascular invasion on oncological outcomes in patients with upper tract urothelial carcinoma after radical nephroureterectomy. BJU Int 2013;111:1199-207.

28. Ouzzane A, Colin P, Xylinas E, Pignot G, Ariane MM, Saint F, et al.; French Collaborative National Database on UUTUC. Ureteral and multifocal tumours have worse prognosis than renal pelvic tumours in urothelial carcinoma of the upper urinary tract treated by nephroureterectomy. Eur Urol 2011;60:1258-65.

29. Dabare AA, Nouri AM, Cannell H, Moss T, Nigam AK, Oliver RT. Profile of placental alkaline phosphatase expression in human malignancies: effect of tumour cell activation on alkaline phosphatase expression. Urol Int 1999;63:168-74. 